\title{
Role of Minimally Invasive Spine Surgery in Adults with Degenerative Lumbar Scoliosis: a Narrative Review
}

Tony Tannoury ${ }^{1}$, Kaveh Haddadi ${ }^{2}$, Harish Kempegowda ${ }^{3}$, Abhijeet Kadam ${ }^{3}$, Chadi Tannoury ${ }^{4}$

${ }^{1}$ MD, Assistant Professor, Orthopedic Spine Surgery, Director of Spine Fellowship Program, Boston University Medical Center, Boston, MA-02118

${ }^{2}$ MD, Associate Professor, Department of Neurosurgery, Spine Fellowship Scholar of Boston University Medical Center. Orthopedic Research Center, Mazandaran University of Medical Sciences, Sari, Iran

${ }^{3}$ MD, Clinical Fellow (Spine Surgery), Department of Orthopedics, Boston University Medical Center, Boston, MA-02118

${ }^{4}$ MD, Assistant Professor, Orthopedic Spine Surgery, Director of Spine Research, Director of Orthopedic Ambulatory Clinic, Co-Director of Spine Fellowship Program, Boston, MA 02118

*Corresponding Author Address: Boston University Medical Center, Boston, Massachusetts-02118, US. Tel:+989111598040. Fax: +981133345273. Email: kh568hd@yahoo.com

Article Type: Review Article

Received: March 3, 2017, Last Revised: August 31, 2017, Accepted: September 14, 2017, Published: September 28, 2017

\section{Abstract}

Background and Aim: Degenerative lumbar scoliosis is a spinal deformity resulting from advanced disc degeneration and facet arthropathy. Given the inconclusive available literature and lack of high-quality data supporting the role of minimally invasive surgical management of degenerative lumbar scoliosis, this review intends to highlight and compare the various viable minimally invasive surgical methods for adult degenerative deformity correction.

Methods and Materials/Patients: Online databases search including Medline, PubMed and Ovid was preformed using the keywords: adult, degenerative, lumbar scoliosis, etiology, clinical issues, diagnostic imaging, spinopelvic alignment, non-operative and surgical treatment options, minimally invasive, interbody fusion, and percutaneous pedicle screw fixation. Eighty-three studies, published after 2000, on degenerative lumbar scoliosis epidemiology, classification and management were identified and reviewed.

Results: Minimally invasive surgical techniques available for interbody fusion include posterior lumbar interbody fusion, transformational lumbar interbody fusion, oblique lumbar interbody fusion, anterior lumbar interbody fusion, and extreme lateral interbody fusion. Each surgical option warrants technical considerations, indication, complications awareness, and functional and radiological outcomes assessment. Sound patients' selection is key for improved outcomes, and therefore the following factors should be well examined prior to surgical intervention: the patient's medical condition and underlying morbidities, the extent of the involved disc spaces, imaging characteristics, and surgeon skills.

Conclusion: The superiority of one surgical technique over the others, was not proven due to lack of strong and supportive data. However, a comprehensive review of indications, benefits, and disadvantages of the minimally invasive surgical procedures is presented. There is an interest in minimally invasive surgery of the spine owing to lower complication rates and morbidity, with limited soft tissue disturbance, decreased blood loss, improved cosmesis, shorter hospital stay, earlier return to work, and therefore decreased general health care costs.

Keywords: Lumbar; Degenerative; Scoliosis; Minimally Invasive; Surgical Procedures

Please cite this paper as: Tannoury T, Haddadi K, Kempegowda H, Kadam A, Tannoury C. Role of Minimally Invasive Spine Surgery in Adults with Degenerative Lumbar Scoliosis: a Narrative Review. Iran J Neurosurg. 2017;3(2):3950. 


\section{Introduction}

Degenerative lumbar scoliosis (DLS) is an adult spinal deformity secondary to accelerated deterioration of the spinal column with advanced disc degeneration and facet arthropathy [1]. This leads to widespread spondylosis which may ultimately leads to spinal segmental instability (lateral listhesis, spondylolisthesis, or vertebral rotation) $[1,2]$. Degenerative scoliosis (de novo) is different from its idiopathic counterpart with regards to etiology, manifestations, and management [3]. DLS is associated with substantial pain due to neurological compression or altered normal spino-pelvic alignment or most often combination of both [4-7].

The management of degenerative scoliosis always remained a major challenge for spine surgeons. Surgical management is reserved for patients who do not respond to conservative treatment. Surgical treatment for spinal deformity are always complex and often associated with many complications (about $80 \%$ ) particularly in the elderly [812].

There has been growing interest in the usage of minimally invasive surgery (MIS) methods for the management of the adult degenerative scoliosis secondary to less morbidity and morbidity including minimal blood loss, less surgical trauma and strain to muscles and paraspinal constructions, reduced analgesic consumption and decreased hospital stay when compared to open spine surgery [13-16]. A. Reported MIS approaches for treatment of degenerative scoliosis stated in the literature include decompression alone, lateral MIS thoracolumbar instrumentation, minimally invasive posterior, transforaminal and anterior fusion methods [17-21]. Given the lack of strong evidence favoring one MIS approach over others, this study was performed to analyze the role of differentMIS methods for adult degenerative deformity with respect to clinical consequences, and fluctuations in radiographic dimensions including spinopelvic angles, lumbar lordosis, and complications.

\section{Methods and Materials/Patients}

We searched Medline, PubMed and Ovid using the following keywords: adult, degenerative, lumbar scoliosis, etiology, clinical issues, diagnostic imaging, spinopelvic alignment, nonoperative and surgical treatment options, minimally invasive, interbody fusion and percutaneous pedicle screw fixation. Our criteria involved articles from journals with detailed description on epidemiology, diagnosis, management, surgical options and clinical outcomes of degenerative lumbar scoliosis in adult patients (age $>45$ years). Exclusion criteria were: 1) articles available in any language other than English, 2) articles published before 2000. Of all articles, 183 articles published from 1978 to 2016 were studied (Figure 1).

\section{Results}

\section{Etiology of Deformity}

Degenerative scoliosis is most often seen in adults above the age of sixty and the reported prevalence is about $12 \%[22,23]$. The disc degeneration leads to decreased disc space height, and subsequently created more pressure on the facets and their degeneration [22], finally leads towards spinal alignment disorders.

In contrast to adolescent idiopathic scoliosis, the degenerative scoliosis curve commonly happens in the lumbar spinal with curves of lesser magnitude [23].

\section{Clinical Issues}

Clinical presentation of adult spinal deformity ranged from minimal symptoms such as mild back pain without radiculopathy to severe back pain with radiculopathy, neurogenic claudication and walking intolerance along with disabling pain $[24,25]$.

It has been shown that the sagittal malalignment is the most common factor responsible for pain and disability in this population $[26,27]$.

\section{Imaging}

Standing full-length 36-inch anteroposterior (AP) and lateral x-rays of the entire spine, iliac crests, and hip joints are necessary for diagnosis, classification and surgical planning. Lateral dynamic lumbar x-rays are helpful to identify local instability or listhesis. Bending imaging 


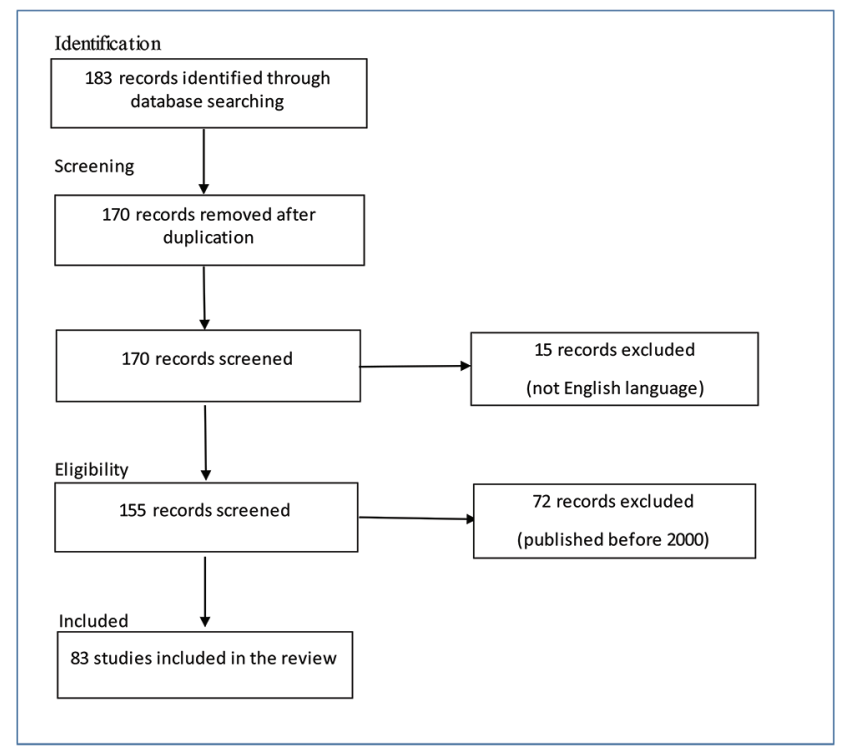

Figure 1. Review Flowchart

may aid in evaluating the flexibility of the scoliotic curve [28]. The Cobb method is used to measure the magnitude of the coronal deformity $[28,29]$. CT scan is useful for bony abnormalities and spinal canal and pedicular dimensions especially before surgery $[30,31]$. MRI needs to be taken to envision any occurrence of canal stenosis, facet hypertrophy, pedicular abnormality, foraminal stenosis, and degenerative disc disease [32-35]. CT-myelography may be used in the setting of pacemakers and rotational deformities for better delineation of bony structures [32]. In patients with possible osteoporosis, a dual- energy x-ray absorptiometry (DEXA) scan may be helpful in pre-operative optimization and surgical planning. [29,30].

\section{Spinopelvic Alignment}

Adult scoliotic patients were found to have lower average lumbar lordosis and grade of thoracic kyphosis than their normal counterparts [33]. A review of literature has revealed numerous relationships between pelvic and spinal variables [33,34]. Pelvic incidence (PI), lumbar lordosis (LL), thoracic kyphosis, sacral slope (SS) and pelvic tilt (PT) are the essential parameters require to measure the magnitude of deformity. [33,34]. Failure to restoration of sagittal balance can lead to poor surgical outcomes. Particular consideration must be given to patients who display high PI as they will need larger rise in lumbar lordosis to restore sagittal balance $[34,36]$. The sagittal variables seem to be more vital in surgical attentions than the coronal deformity. [36].

\section{Osteoporosis}

Osteoporosis is diagnosed when T-scores of less than -2.5 in DEXA scan $[37,38]$. Osteoporotic patients require different strategic plan when it comes to the instrumentation such as several locations of fixation, augmentation with cement, and lesser degrees of deformity correction $[38,39]$.

\section{Treatment}

Numerous factors, such as medical comorbidities, social, and ecological issues have been shown to be important determinants in the treatment choices. Hence, detailed multi-disciplinary therapy is critically vital in determining a suitable treatment strategy $[40,41]$.

\section{Non-operative Treatment}

Patients with minimal or no symptoms just need a routine and intermittent followup to monitor curve progression $[40,41]$. Non-surgical interventions, such as pharmacologic intervention, physical and aquatic therapy, chiropractic manipulation and yoga among others are acceptable treatment choices but have unverified longterm effectiveness in adults with scoliosis 


\section{[41-44].}

The use of a spine orthosis may offer short-term pain relief, nonetheless longterm usage results in muscle weakness, and has no influence on curve progress [40]. Epidural and facet injections, selective nerve root blocks, and trigger point injections have a limited role in treatment and diagnosis. The preservation of an active level of physical activity and lifestyle in adult deformity patients is vital $[42,45]$.

\section{Surgical Treatment}

Patients with radiculopathy or stubborn back pain in spite of undergoing sufficient non-operative treatments and with neurological disorders may be surgical candidates. The surgical choice depends on medical co-morbidities, age, and prior operation history, social, and mental aspects and life expectancy [40]. Since recovery from deformity surgery is often prolonged and may necessitate inpatient rehabilitation in addition to repeated appointments with healthcare providers, making patients' family aware of this issue is obligatory before undertaking such surgery and throughout the recovery period. Recognition and treatment of osteoporosis is essential and may require delaying the surgery 6-18 month while pharmacological intervention is taking place [40,41]. Most common indications for surgery are devastating pain unresponsive to non-operative approaches and severely disturbing the quality of life, neurological disorders, and infrequently cosmetic appearance $[40,44,45]$. The goal of surgery is the decompression of neural elements by restoration and the maintenance of sagittal and coronal balance $[42,46]$. Decompression only is seldom an option and large fusion in addition to the decompression is the most likely choice in the vast majority of scoliotic deformities [46].

\section{Decompression Only}

Decompression can be done in slight degenerative curves without instability with a well-defined radiculopathy with no back pain; however, it can probably lead to additional postsurgical spinal instability $[7,22]$. The results of some studies on clinical consequences in patients with degenerative scoliosis showed the efficiency of minimally invasive decompression specially in isolated lateral listhesis [42-45].

\section{Posterior Methods}

The posterior approaches in handling adult lumbar deformity have been used since long time ago. These include traditional laminectomy, posterolateral instrumented fusion and preferably augmented with interbody fusion via posterior lumbar interbody fusion (PLIF) or transforaminal lumbar interbody fusion (TLIF) [46,47]. There are some early encouraging results with techniques using less invasive posterior decompression and percutaneous fusion processes for the lumbar degenerative deformities $[47,48]$.

\section{Anterior Method Alone}

Anterior lumbar discectomy and fusion with instrumentation have been shown to have outstanding deformity improvement and great patient satisfaction in well selected patients. Anterior only surgery, however, did not receive wide acceptance due to major potential complications, limited options for fixation, limited decompression and difficulty maintaining deformity correction [49,50]. Claimed benefits of anterior only surgery include powerful curve correction, reliable fusion, fewer fused discs in the lumbar spine and preservation of the posterior lumbar musculature [51,52]. Despite the advantages of an anterior approach, there are some probable complications related to this technique, which include ileus, vascular injury, and iliac artery thrombosis, pseudarthrosis, nerve damages, subsidence, loss of correction or graft dislocation, ureter injury, abdominal hernia, and retrograde ejaculation in male $[52,53]$.

\section{Combined Anterior-Posterior Fusion}

A combined anterior and posterior approach is essential for severe deformities in both coronal and sagittal planes $[23,54]$. In spite of increased surgery time and potential complication and morbidity rate $[23,55]$, studies proved higher fusion rates, greater degree of deformity correction, and superior general outcomes [23,29,56,57]. Studies showed that combined anterior 
lumbar interbody fusion (ALIF) and instrumented posterolateral fusion for adult DLS improve sagittal and coronal plane arrangement more efficiently compared to posterior only group [58-61].

\section{Minimally Invasive Decompression and Fixation Methods in the Management of Degenerative Deformity Conditions}

Minimally invasive decompression and fixation methods have shown improved results compared with nonsurgical approaches, but these methods are challenging for the surgeon and demanding for the patient. Surgical challenges are mainly reestablishment of global spinal alignment, adequate decompression and successful fusion with less complications [62-65].

Although the definitive comparative results about superiority of MIS methods over open techniques have not become clear so far, most literature reports agree with this theory that complication rates, surgery time and blood loss in MIS methods were found to be lower, and ambulation after surgery and return to work happens earlier than those in open procedures [65-68]. The advance of novel procedures leads to reduce surgery time and attain faster recovery through decreasing surgery complications $[68,69]$. Lumbar interbody fusion (LIF) is a recognized management for handling a variety of spinal complaints including degenerative diseases, infections, neoplasia and trauma [65]. LIF includes placement of an implant (cage or graft) inside the intervertebral space once discectomy and endplate preparation have been done. Different techniques have been described such as: PLIF, TLIF or minimally invasive TLIF (MI-TLIF), oblique lumbar interbody fusion/anterior to psoas (OLIF/ATP), ALIF, and lateral lumbar interbody fusion (direct lateral interbody fusion or DLIF, LLIF or XLIF etc...). There is no strong indication for one method being superior to others $[66,67]$.

\section{PLIF}

In the PLIF procedure, surgical entry to the disc space is achieved from a posterior pathway. The patient is firstly placed in a prone position on a Jackson table. Moreover, an open midline method through bilateral muscle strip dissection or MIS paramedian Wiltsy approach can be done to reach the posterior part of the vertebra [70-72]. After wide laminotomy, the dura is retracted to expose the disc space. Contraindications for posterior fusion operation include arachnoiditis, widespread epidural scarring, and infection. There are numerous advantages related to PLIF surgical procedure. Initially, the PLIF method is a conventional lumbar approach in which most spinal surgeons are well-skilled and experienced. A posterior access allows outstanding visualization of the nerve roots deprived of affecting blood supply to the graft [72,73]. PLIF allows reliable neurological decompression, satisfactory interbody fusion and disc height restoration [74]. Potential disadvantages $[74,75]$, however, may be substantial paraspinal damage linked to long-term muscle retraction, battered root syndrome, and limited ability to achieve adequate lordosis consistently [73-75].

\section{TLIF}

TLIF is a posterior approach for fusion with the patient in prone position designed for treatment of degenerative lumbar disease after unsuccessful conventional medical care $[73,74]$. This approach is similar to PLIF except that the disc is entered from a more lateral angulation with unilateral laminectomy, full facetectomy, and partial pars excision allowing easy access to the disc space through the Cambian triangle, a safe zone between the exiting nerve root, traversing nerve root, and the dura. TLIF can be done through an open midline incision or MIS technique via small paramedian incision [73,74]. Indications and contraindications are similar to those in PLIF. The benefits of the TLIF over the PLIF is the ability to perform the interbody fusion with less retraction and manipulation of the neural elements and ability to place larger cage. The TLIF approach maintains important midline ligaments [73,76-78].

Similar to PLIF, the TLIF can be 
associated with substantial paraspinal damage with prolonged muscle retraction particularly when done via open midline incision in addition to the limited ability to restore sagittal plane [77-79].

\section{ALIF}

The anterior retroperitoneal approach offers very generous access to the whole ventral part of the disc space, permitting complete discectomy and inserting straight implant. Patient is placed in supine or lateral position. The incision can be midline, paramedian or Pfannenstiel (L5/S1) incision with a retroperitoneal passage and vascular mobilization and dissection. The ALIF method is appropriate for levels L3/4, L4/ L5 and L5/S1 [80,81]. An ALIF technique may be proper for degenerative diseases, and improvement of failed back syndrome [80,81]. Contraindications of ALIF include substantial previous abdominal surgery with adhesions or adverse vascular anatomy, serious peripheral vascular illness, solitary kidney on exposure side, spinal infection and high-grade spondylolisthesis without posterior fusion $[81,83]$. Isthmic spondylolisthesis at L5/S1 is a relative contraindication [80-83], and should be supplemented with posterior fixation. The ALIF approach is related to numerous important advantages. Initially, this method permits straight midline vision of the disc space and wide lateral exposure of the vertebral bodies, which allows effective disc space clearance with quick endplate preparation. Also, the anterior entry permits expansion of the implant dimensions and surface area, that simplifies aggressive correction of lordosis and foraminal height restoration. This can lead to great fusion rates through ample disc space preparation [82-84]. This also permits preservation of posterior spinal muscles and psoas muscles, which could decrease pain and disability after surgery. Disadvantages of the ALIF method comprise possible complications such as retrograde ejaculation, visceral and vascular damage [83-85]. Figure 2 shows surgery process of DLS patient in Boston medical center.

\section{XLIF}

The LLIF, DLIF or XLIF procedure defined by Ozgur et al. in 2006 necessitates entering the disc space through a lateral retroperitoneal, transpsoas passage [86]. Placed in lateral position, the patient underwent direct lateral incision followed by splitting the psoas muscle while performing neuromonitoring and docking on the intervertebral disc. LLIF is appropriate for discs from L1/L2 to L4/5. This method is not appropriate for the L5/S1 level, owing to the position of the iliac crest that blocks lateral entry.

Advantages of such approach are the MIS muscle splitting method that allows accessing multiple discs and placement of large interbody cage with varying degree of lumbar lordosis [86-89].

Disadvantages include possible dangers of bowel or vascular injuries and injuries to the lumbar plexus. As the lumbar plexus is located more anteriorly in the psoas as we go distally, such injuries increase with lower levels such as L4/5 level [88]. The main disadvantages of this technique is the inability to access L5-S1 that is often affected and need to be included in the surgical fix. This often leads to improper choice of the extent of fusion and subsequently unacceptable rate of adjacent level disease. In addition, the psoas muscle will make adequate anterior release risky and therefore, the surgeon often damages the endplate without being able to perform adequate and lasting sagittal balance [8688]. The XLIF approach cannot be suitable for central canal stenosis, lateral recess stenosis, and high-grade spondylolisthesis [87]. The lateral method is also not fit in patients with previous retroperitoneal operation or with retroperitoneal abscess, as well as patients with adverse vascular anatomy.

Vascular injury, if it happens, may be hard to manage, and this is an another hazard of the lateral trans-psoas approach $[88,89]$.

\section{Anterior to the Psoas: ATP/OLIF}

The ATP/OLIF method involves an MIS entry to the disc space through flank incision and retroperitoneal approach to the spine. This utilizes and develops the space between the psoas and the anterior vessels and bowels. 
With the patient in lateral decubitus position, this technique allows access to the spine from T12-S1 through one single small incision without the need to dissect through the Psoas muscle and risking the lumbar plexus [90,91]. A lateral and paramedian cutting is performed [82]. Neuromonitoring is not essential as the corridor anterior to the psoas muscle is utilized for entry. Indications for ATP/OLIF include all degenerative conditions and is very effective for achieving reliably and consistently sagittal and coronal deformity balance.

Unlike the direct lateral procedures (DLIF, XLIF, LLIF, etc....), the ATP/OLIF yields to full anterior release, and disc opening allowing the surgeon to perform direct as well as indirect decompression. The L5-S1 is easily accessible when needed giving the surgeon a great opportunity to gain substantial lordosis, solid L5-S1 fusion, strong anterior column support reducing the loads and stresses on the posterior fixations [82,90,91].

Potential complications can include vascular, bowel injuries, and sympathetic plexus, but such risk is much reduced by the ability of the surgeon of direct visualization of these structures [91,92].

\section{Which MIS Approach is Better?}

There is a large body of literature discussing radiological and clinical outcomes following specific interbody surgery; however, there is little definitive data comparing existing methods.

Surgeons who have been practiced in one particular interbody procedure will have a propensity to advocate that method. The literature consistently supports the idea of interbody methods for sagittal and coronal plane deformities [93,94].

New studies showed that interbody fusion procedures (LIF, ALIF and TLIF) create significantly higher segmental lordosis alteration compared to posterior spinal fusion [94-96]. ALIF was shown to have better restoration of lumbar lordosis versus TLIF. Segmental correction with ALIF achieved local disc angle by $8.3^{\circ}$ and lumbar lordosis by $6.2^{\circ}$, while TLIF reduced the local disc angle by $0.1^{\circ}$ and lumbar lordosis by $2.1^{\circ}$. Likewise, Kim et al. stated that the variation of disc height, segmental lordosis, and lumbar lordosis before and after operation in ALIF were higher than those in TLIF [97].

Clinical results in ALIF were comparable to those in TLIF $[96,97]$. But, Kim et al. stated that the Oswestry disability index (ODI) score in TLIF is higher than that in ALIF at L4-5, but not L5-S1, and they advise that mini-TLIF is desirable at the L4-5 level, while mini-ALIF may be better at the L5-S1 level for the treatment of isthmic spondylolisthesis [97].

Others propose that anterior methods are better than posterior ones in terms of disc height restoration, lumbar lordosis and deformity improvement, and that clinical outcomes and fusion rates were similar to those in posterior procedures. But this information is based on different studies with numerous indications and comparison is hard to make [98].

Ming-Kai et al. in 2015 reported their results based on 110 operated patients data between November 2002 and November 2011, and showed that combined ALIF and instrumented posterolateral fusion for adult DLS improved sagittal and coronal plane alignment more effectively than posterior group while both groups improved clinical scores effectively [60].

After rearrangement of the available data in the writings, Ralph J. Mobbs et al. have suggested the following recommendations based on the level of pathology and indication [20].

\section{L5/S1}

I.ALIF is selected method for discogenic low back pain (LBP) and lordosis restoration;

II. PLIF and TLIF are advisable approaches particularly with central canal stenosis or recurrent disc herniation;

III. PLIF is selected method for isthmic spondylolisthesis owing to the high risk of L5 nerve injury;

IV. ATP/OLIF early data are promising and excellent for L5/S1.

\section{$L 4 / 5$}

I. PLIF and TLIF are good choices for degenerative spondylolisthesis;

II. ALIF/ATP/OLIF/XLIF all are advisable choices for lordosis and deformity 
correction, but XLIF has a bigger risk of lumbar plexus/psoas damage.

\section{$L 2 / 3$ and $L 3 / 4$}

I. All methods excluding supine ALIF are suitable;

II. Supine ALIF is not suggested due to high risk; it needs skillful vascular surgical assistance;

III. For deformity correction, antero-lateral methods including LLIF/ATP/OLIF are favored.

\section{$T 12 / L 1$ and $L 1 / 2$}

I. ALIF is not appropriate, but ATP/OLIF is a suitable method;

II. PLIF/TLIF are hard if cord or conus inhibits dural retraction for insertion of implant/s;

III. XLIF is a proper choice especially for deformity correction.

\section{Multilevel}

I. Multilevel frequently requires deformity correction if done for degenerative pathologies;

II. Combination of anterior/lateral and posterior methods offers powerful deformity correction;

III. Multilevel ALIF/LLIF/OLIF offer the most powerful sagittal and coronal correction; however, they require additional posterior fixation.

\section{Percutaneous Pedicle Screw Fixation}

Pedicle screw instrumentation is a great supplement to interbody lumbar fusion and provide powerful deformity correction.

The safety of conventional open methods for pedicle screw insertion has been well recognized; but owing to high level of surgical complications that average 35\%, various MIS methods will continue to rise $[99,100]$. The primary change has a sharp learning curve; but there are numerous basic concepts which can help the surgeon in safe application of the Jamshidi needle into a thoracic or lumbar pedicle [101].

Traditional open spine surgery has numerous reported complications including postoperative muscle pain, blood loss, and surgical wound infection. The paraspinal muscle dissection implicated in open spine surgery can lead to muscular denervation, augmented intramuscular pressure, ischemia, and necrosis giving rise to muscle atrophy and scarring, and sustained pain and disability $[102,103]$. There is no available study of high-quality demonstration showing MIS is better than open surgery; but there is a tendency towards MIS options having lower complication rates and morbidity, with negligible soft tissue disturbance, decreased blood loss and danger of transfusion, better cosmetics, less hospital stays, earlier return to work, and therefore diminished general health care prices [101,102,104].

Notwithstanding this, many raised concerns that MIS is related to imperfect results for adult deformity mainly due to significantly reduced visualization with MIS [105] in addition to the increased radiation exposure $[105,106]$.

\section{Limitations}

The limits of the present review include the absence of straight comparison between the different MIS methods. This information is established on different studies with multiple pathologies and different surgeons and health-care centers. In addition, most studies lacked important radiological methods and reportings. Thus conclusions should be carefully chosen.

While TLIF, PLIF and ALIF are frequently used procedures for LIF, the anterior to the Psoas (ATP/OLIF) showed significantly superior results based on the data that will be published in the near future by the authors of this report. The ATP will prove to be an excellent choice for one level disease and degenerative scoliosis

\section{Conclusion}

Degenerative adult deformity is a complex issue that affects the quality of life of very large percentage of aging population and whose surgical treatment is very helpful despite high percentage of perioperative complications. We believe the MIS options are ideal as long as they are able to achieve the goal of the surgery but not limited to adequate spinal alignment and faster surgery time and less complications. Of the MIS options that are available now, the anterior to the psoas, based on the authors' experience, seems to be the most reliable and consistent technique to be used. 

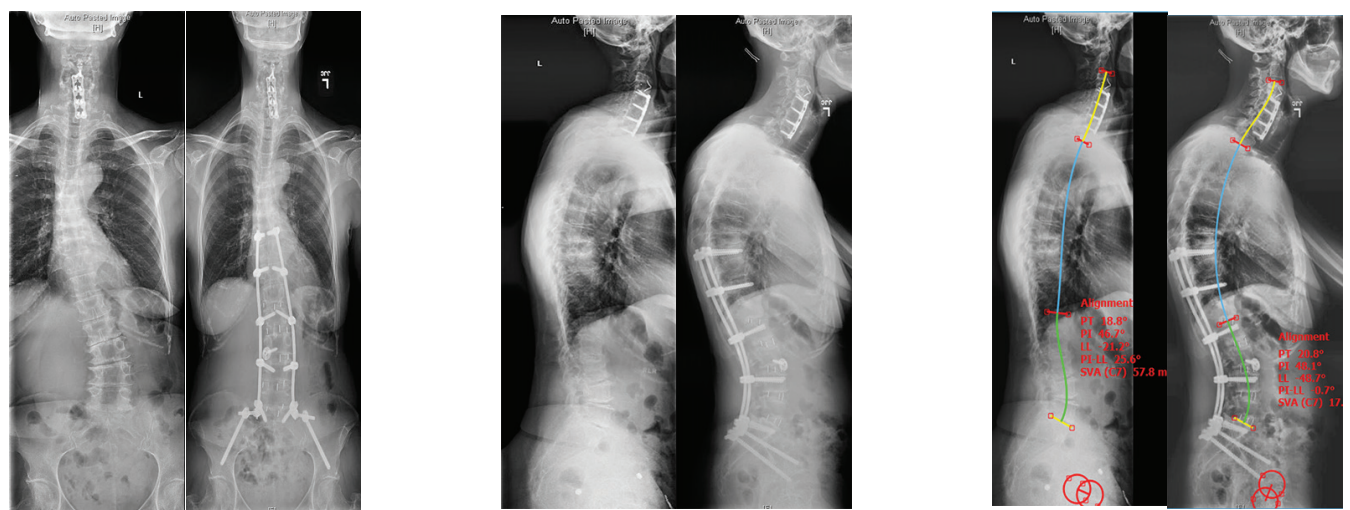

Figure 2. A 62-Year-Old Female with Adult Kyphoscoliosis Deformity. Pre-operative Images Showing Cobb Angle of 300 in Coronal Plane with Sagittal PI-LL Mismatch of 25.60 and Lumbar Lordosis of 210 (Left-sided Images). The Patient Was Treated by MIS ATP Approach Anterior and Posterior Fusion. Post-operative Images Showing Neutral Alignment in Coronal Plane, PI-LL Mismatch Corrected to 0.70 and Lumbar Lordosis Restored to 48.70 (Right-sided Images).

\section{Funding \\ None}

\section{Conflicts of Interests}

Not declared.

\section{Authors' Contribution}

Conception and Design: Abhijeet Kadam, Kaveh Haddadi

Data Collection: Abhijeet Kadam, Kaveh Haddadi

Drafting the Article: Abhijeet Kadam

Critically Revising the Article: Tony Tannoury, Chadi Tannoury, Harish Kempegowda Reviewed Submitted Version of the Manuscript: Kaveh Haddadi, Harish Kempegowda Approved the Final Version of the Manuscript: Tony Tannoury, Chadi Tannoury

\section{References}

1. Adam S. Kanter M, Ashok R., Asthagiri, Christopher I, Shaffrey. Aging Spine: Challenges and Emerging Techniques. Clinical Neurosurgery .2007;54:10-18.

2. Anasetti F, Galbusera F, Aziz HN, Bellini CM, Addis A, Villa T. et. Al. Spine stability after implantation of an interspinous device: an in vitro and finite element biomechanical study. J Neurosurg Spine .2010;13(5):568-75.

3. Aebi M. The adult scoliosis. Eur Spine J .2005;14(10):92548

4.Liu W, Chen XS, Jia LS, Song DW. The clinical features and surgical treatment of degenerative lumbar scoliosis: a review of 112 patients. Orthop Surg .2009;1:176-183.

5. Ploumis A, Transfeldt EE, Gilbert TJ Jr, Mehbod AA, Dykes DC, Perra JE. Degenerative lumbar scoliosis: radiographic correlation of lateral rotatory olisthesis with neural canal dimensions. Spine. 2006;31:2353-2358.

6.Kelleher MO, Timlin M, Persaud O, Rampersaud YR. Success and failure of minimally invasive decompression for focal lumbar spinal stenosis in patients with and without deformity. Spine. 2010;35:E981-E987.

7. Matsumura A, Namikawa T, Terai H, Tsujio T, Suzuki A, Dozono S, et al. The influence of approach side on facet preservation in microscopic bilateral decompression via a unilateral approach for degenerative lumbar scoliosis. Clinical article. J Neurosurg Spine. 2010;13:758-765.

8. Yamada K, Matsuda H, Nabeta M, Habunaga H, Suzuki A, Nakamura H. Clinical outcomes of microscopic decompression for degenerative lumbar foraminal stenosis: a comparison between patients with and without degenerative lumbar scoliosis. Eur Spine J. 2011;20:947-953.

9.Cho KJ, Suk SI, Park SR, Kim JH, Kim SS, Choi WK, et al: Complications in posterior fusion and instrumentation for degenerative lumbar scoliosis. Spine. 2007:32:2232-2237. 10. Schwab F, Farcy JP, Bridwell K, Berven S, Glassman S, Harrast J, et al: A clinical impact classification of scoliosis in the adult. Spine. 2006;31:2109-2114

11. Ali RM, Boachie-Adjei O, Rawlins BA: Functional and radiographic outcomes after surgery for adult scoliosis using third-generation instrumentation techniques. Spine. 2003;28:1163-1170.

12. Bess RS, Lenke LG, Bridwell KH, Cheh G, Mandel $\mathrm{S}$, Sides B: Comparison of thoracic pedicle screw to hook instrumentation for the treatment of adult spinal deformity. Spine. 2007;32:555-561.

13. Cho KJ, Suk SI, Park SR, Kim JH, Kang SB, Kim HS, et al: Risk factors of sagittal decompensation after long posterior instrumentation and fusion for degenerative lumbar scoliosis. Spine. 2010;35:1595-1601.

14. DeWald CJ, Stanley T: Instrumentation-related complications of multilevel fusions for adult spinal deformity patients over age 65 : surgical considerations and treatment options in patients with poor bone quality. Spine. 2006;31(19):S144-S151.

15. Isaacs RE, Hyde J, Goodrich JA, Rodgers WB, Phillips FM. A prospective, nonrandomized, multicenter evaluation of extreme lateral interbody fusion for the treatment of adult degenerative scoliosis: perioperative outcomes and complications. Spine. 2010;35(26 Suppl):S322-S330.

16. Khan SN, Hofer MA, Gupta MC: Lumbar degenerative scoliosis: outcomes of combined anterior and posterior pelvis surgery with minimum 2-year follow-up. Orthopedics. 2009;32(4):258

17. Peelle MW, Boachie-Adjei O, Charles G, Kanazawa Y, Mesfin A: Lumbar curve response to selective thoracic fusion in adult idiopathic scoliosis. Spine J. 2008;8:897903.

18. Wang MY, Mummaneni PV: Minimally invasive surgery for thoracolumbar spinal deformity: initial clinical experience with clinical and radiographic outcomes. Neurosurg Focus. 2010;28(3):E9.

19. Zhang H, Gao Q, Wang Y, Liu S, Guo C, Tang M, et al: Clinical evaluation of indirect decompression treatments for 
degenerative adult idiopathic scoliosis. Arch Orthop Trauma Surg. 2011;131:1639-1647.

20. Mobbs RJ, Phan K, Malham G, et al. Lumbar interbody fusion: techniques, indications and comparison of interbody fusion options including PLIF, TLIF, MITLIF, OLIF/ATP, LLIF and ALIF. J Spine Surg .2015;1:2-18.

21. Deutsch H, Musacchio MJ Jr. Minimally invasive transforaminal lumbar interbody fusion with unilatera pedicle screw fixation. Neurosurg Focus .2006;20:E10.

22. Youssef JA, Hamlin LF. Adult spinal deformity. In: Lieberman JR, ed. Orthopaedic Board Review Manual. Rosemont, IL: American Academy of Orthopaedic Surgeons. 2009;721-726.

23. Gupta MC. Degenerative scoliosis. Options for surgical management. Orthop Clin North Am .2003;34:269-279.

24. Lestini WF, Fulghum JS, Whitehurst LA. Lumbar spinal fusion: advantages of posterior lumbar interbody fusion. Surg Technol Int. 1994;3:577-90.

25. Cole CD, McCall TD, Schmidt MH, et al. Comparison of low back fusion techniques: transforaminal lumbar interbody fusion (TLIF) or posterior lumbar interbody fusion (PLIF) approaches. Curr Rev Musculoskelet Med. 2009;2:118-26.

26.Ailon T, Smith JS, Shaffrey CI, et al. Degenerative Spinal Deformity. Neurosurgery. 2015;77 (Suppl 4): S75-91. Neurosurgery. 2011;69:1181-1187.

27. Waddell B, Briski D, Qadir R, et al. Lateral lumbar interbody fusion for the correction of spondylolisthesis and adult degenerative scoliosis in high-risk patients: early radiographic results and complications. Ochsner $\mathrm{J}$ .2014;14:23-31.

28. Crawford $\mathrm{CH}$, Glassman SD. Fusing adult degenerative deformities of the lumbar spine. Semin Spine Surg. 2011;23:222-226

29. Tormenti MJ, Maserati MB, Bonfield CM, Okonkwo DO, Kanter AS. Complications and radiographic correction in adult scoliosis following combined transpsoas extreme lateral interbody fusion and posterior pedicle screw instrumentation. Neurosurg Focus. 2010;28:E7-E13.

30. Lotfinia I,Haddadi K,Sayyahmelli S.computed tomographic evaluatin of pedicle dimension and lumbar spinal canal. neurosurgery quaterly. 2010;20(3):194-198.158.

31. Ahmad Ghasemi, Kaveh Haddadi, Mohammad Khoshakhlagh, and Hamid Reza Ganjeh. The Relation between Sacral Angle and Vertical Angle of Sacral Curvature and Lumbar Disc Degeneration. Medicine. 2016; 95(6):2746.

32. Fu KM, Rhagavan P, Shaffrey CI, Chernavvsky DR, Smith JS. Prevalence, severity, and impact of foraminal and canal stenosis among adults with degenerative scoliosis. Neurosurgery. 2011;69:1181-1187.

33. Mendoza-Lattes S, Ries Z, Gao Y, Weinstein SL. Natural history of spinopelvic alignment differs from symptomatic deformity of the spine. Spine. 2010;35:E792-E798.

34. Patel AA, Daubs M. Spinal-pelvic relationships: implications for spine surgery. SpineLine. 2010;11(2):18-21. 35. Ahmad Ghasemi, Kaveh Haddadi, and Ali Ahmadi Shad. Comparison of Diagnostic Accuracy of MRI With and Without Contrast in Diagnosis of Traumatic Spinal Cord Injuries. Medicine. 2015;94(43):1942.

36. Lafage V, Schwab F, Vira S, Patel A, Ungar B, Farcy JP. Spino-pelvic parameters after surgery can be predicted: a preliminary formula and validation of standing alignment. Spine. 2011;36:1037-1045.

37. Silva FE, Lenke LG. Adult degenerative scoliosis: evaluation and management. Neurosurg Focus. 2010;28: E1-E10.

38.Sirola J, Rikkonen T, Tuppurainen M, Honkanen R, Kröger H. Should risk of bone fragility restrict weight control for other health reasons in postmenopausal women? A ten-year prospective study Maturitas. 2012;71:162-168.

39. Russo A, Bransford R, Wagner T, Lee MJ, Chapman JR. Adult degenerative scoliosis insights, challenges, and treatment outlook. Curr Orthop Pract. 2008;19:357-365. 40. Avraam Ploumis, Ensor E. Transfledt, Francis Denis. Degenerative lumbar scoliosis associated with spinal stenosis. The Spine Journal. 2007;7(4):428-36.

41. Schwab F, el-Fegoun AB, Gamez L, Goodman H, Farcy JP. A lumbar classifcation of scoliosis in the adult patient: preliminary approach. Spine. 2005;30(14):1670-1673.

42. Oskouian RJ Jr, Shaffrey CI. Degenerative lumbar scoliosis. Neurosurg Clin N Am. 2006;17(3):299-315.

43. Kaveh Haddadi, Leila Asadian and Ahdie Isazade. Effects of Nasal Calcitonin vs. Oral Gabapentin on Pain and Symptoms of Lumbar Spinal Stenosis: A Clinical Trial Study. Clinical Medicine Insights: Arthritis and Musculoskeletal Disorders. 2016:9;133.

44. Tribus CB. Degenerative lumbar scoliosis: evaluation and management. J Am Acad Orthop Surg. 2003;11(3):17483 .

45. Kaveh Haddadi, Hamid Reza Ganjeh Qazvini. Outcome after surgery of lumbar spinal stenosis: a randomized comparison of bilateral laminotomy, Trumpet laminectomy, and conventional laminectomy Frontiers in Surgery. 2016; 31(4):E6.

46. Yadla S, Maltenfort MG, Ratliff JK, Harrop JS: Adult scoliosis surgery outcomes: a systematic review. Neurosurg Focus. 2010;28(3):E3.

47. Matsumura A, Namikawa T, Terai $\mathrm{H}$, et al. The influence of approach side on facet preservation in microscopic bilateral decompression via a unilateral approach for degenerative lumbar scoliosis. Clinical article. J Neurosurg Spine. 2010;13:758-765.

48. ransfeldt EE, Topp $\mathrm{R}$, Mehbod AA, Winter RB. Surgical outcomes of decompression, decompression with limited fusion, and decompression with full curve fusion for degenerative scoliosis with radiculopathy. Spine 2010; 35:1872-1875

49. Vaccaro AR, Ball ST: Indications for instrumentation in degenerative lumbar spinal disorders. Orthopedics. 2000; 23:260-271.

50. Majd ME, Castro FP Jr, Holt RT. Anterior fusion for idiopathic scoliosis. Spine. 2000;25:696-702.

51. Simmons ED. Surgical treatment of patients with lumbar spinal stenosis with associated scoliosis. Clin Orthop Relat Res. 2001;384:45-53.

52. Than KD, Wang AC, Rahman SU, et al. Complication avoidance and management in anterior lumbar interbody fusion. Neurosurg Focus. 2011;31(4):E6.

53. Guyer RD, Fulp T. Perirectus retroperitoneal approach for anterior lumbar interbody fusion. In: Zdeblick TA, ed. Anterior Approaches to the Spine. St. Louis, MO: Quality Medical Publishing, Inc. 1999:203-216.

54. Zdeblick TA. Mini-ALIF with cages. In: Bradford DS, Zdeblick TA, eds. Master Techniques in Orthopaedic Surgery: The Spine, 2nd ed. Philadelphia, PA: Lippincott Williams \& Wilkins; 2004:321-333.

55. Sengupta K. Adult spinal deformity. In: Rao RD, Smuck M, eds. Orthopaedic Knowledge Update: Spine,

4th ed. Rosemont, IL: American Academy of Orthopaedic Surgeons; 2012:349-367.

56. Mundis GM, Akbarnia BA, Phillips FM. Adult deformity correction through minimally invasive lateral approach techniques. Spine. 2010;35(26, Suppl): S312-S321.

57. Anand N, Baron EM, Thaiyananthan G, Khalsa K, Goldstein TB. Minimally invasive multilevel percutaneous correction and fusion for adult lumbar degenerative scoliosis: a technique and feasibility study. J Spinal Disord Tech. 2008; 21:459-467.

58. Good CR, Lenke LG, Bridwell KH, et al. Can posterior only surgery provide similar radiographic and clinical results as combined anterior (thoracotomy/thoracoabdominal)/ posterior approaches for adult scoliosis? Spine. 2010; 35:210-218.

59. Wang MY. PLIF for the treatment of adult spinal deformity. Acta Neurochir (Wien) 2011;153:557. 
60. Resnick DK. Lumbar interbody fusion: current status. Contemporary Spine Surgery. 2009;10:1-6.

61. Ming-Kai Hsieh, et al. Combined anterior lumbar interbody fusion and instrumented posterolateral fusion for degenerative lumbar scoliosis: indication and surgical outcomes. BMC Surgery. 2015;15:26.

62. Rao PJ, Ghent F, Phan K, et al. Stand-alone anterior lumbar interbody fusion for treatment of degenerative spondylolisthesis. J Clin Neurosci. 2015;22:1619-2.

63. Malham GM, Parker RM, Goss B, et al. Clinical results and limitations of indirect decompression in spinal stenosis with laterally implanted interbody cages: results from a prospective cohort study. Eur Spine J. 2015;24 Suppl 3:339-

64. Zhu Y, Liu HY, Wang B, et al. Long-term clinical outcomes of selective segmental transforaminal lumbar interbody fusion and posterior spinal fusion for degenerative lumbar scoliosis. Zhonghua Yi Xue Za Zhi. 2013;93:357781.

65. Manwaring JC, Bach K, Ahmadian AA, et al Management of sagittal balance in adult spinal deformity with minimally invasive anterolateral lumbar interbody fusion: a preliminary radiographic study. J Neurosurg Spine. 2014;20:515-22.

66.Resnick DK, Choudhri TF, Dailey AT, et al. Guidelines for the performance of fusion procedures for degenerative disease of the lumbar spine. Part 7: intractable lowback pain without stenosis or spondylolisthesis. J Neurosurg Spine. 2005;2:670-2

67. Eck JC, Hodges S, Humphreys SC. Minimally invasive lumbar spinal fusion. J Am Acad Orthop Surg. 2007;15:3219.

68. Mobbs RJ, Sivabalan P, Li J. Minimally invasive surgery compared to open spinal fusion for the treatment of degenerative lumbar spine pathologies. J Clin Neurosci. 2012;19:829-35.

69. Phan K, Rao PJ, Scherman DB, et al. Lateral lumbar interbody fusion for sagittal balance correction and spinal deformity. J Clin Neurosci. 2015;22:1714-21.

70. Briggs H, Milligan PR. Chip fusion of the low back following exploration of the spinal canal. J Bone Joint Surg Am. 1944;26:125-30.

71. Harms J, Rolinger H. A one-stager procedure in operative treatment of spondylolistheses: dorsal traction-reposition and anterior fusion (author's transl). Z Orthop Ihre Grenzgeb 1982;120:343-7.

72. Cole CD, McCall TD, Schmidt MH, et al. Comparison of low back fusion techniques: transforaminal lumbar interbody fusion (TLIF) or posterior lumbar interbody fusion (PLIF) approaches. Curr Rev Musculoskelet Med. 2009;2:118-26. 73.Fan SW, Hu ZJ, Fang XQ, et al. Comparison of paraspinal muscle injury in one-level lumbar posterior inter-body fusion: modified minimally invasive and traditional open approaches. Orthop Surg. 2010;2:194-200.

74. Park J, Kim Y, Hong H, et al. Comparison between posterior and transforaminal approaches for lumbar interbody fusion. J Korean Neurosurg Soc. 2005;37:340-4.

75. Humphreys SC, Hodges SD, Patwardhan AG, et al. Comparison of posterior and transforaminal approaches to lumbar interbody fusion. Spine. 2001;26:567-71.

76. Zhang Q, Yuan Z, Zhou M, et al. A comparison of posterior lumbar interbody fusion and transforaminal lumbar interbody fusion: a literature review and metaanalysis. BMC Musculoskelet Disord. 2014;15:367.

77. Hsieh PC, Koski TR, O'Shaughnessy BA, et al. Anterior lumbar interbody fusion in comparison with transforaminal lumbar interbody fusion: implications for the restoration of foraminal height, local disc angle, lumbar lordosis, and sagittal balance. J Neurosurg Spine. 2007;7:379-86.

78. Phan K, Thayaparan GK, Mobbs RJ. Anterior lumbar interbody fusion versus transforaminal lumbar interbody fusion - systematic review and meta-analysis. $\mathrm{Br}$
Neurosurg. 2015;29(5):705-11.

79. Audat Z, Moutasem O, Yousef K, et al. Comparison of clinical and radiological results of posterolateral fusion, posterior lumbar interbody fusion and transforaminal lumbar interbody fusion techniques in the treatment of degenerative lumbar spine. Singapore Med J. 2012;53:183-7. 80. Sakeb N, Ahsan K. Comparison of the early results of transforaminal lumbar interbody fusion and posterior lumbar interbody fusion in symptomatic lumbar instability. Indian J Orthop. 2013;47:255-63.

81. Rao PJ, Loganathan A, Yeung V, et al. Outcomes of anterior lumbar interbody fusion surgery based on indication: a prospective study. Neurosurgery 2015;76:7-23; discussion 23-4

82. Malham GM, Parker RM, Ellis NJ, et al. Anterior lumbar interbody fusion using recombinant human bone morphogenetic protein-2: a prospective study of complications. J Neurosurg Spine. 2014;21:851-60.

83. Ohtori S, Mannoji C, Orita S, et al. Mini-Open Anterior Retroperitoneal Lumbar Interbody Fusion: Oblique Lateral Interbody Fusion for Degenerated Lumbar Spinal Kyphoscoliosis. Asian Spine J .2015;9:565-72.

84. Phan K, Mobbs RJ. Sacrum fracture following L5-S1 stand-alone interbody fusion for isthmic spondylolisthesis. J Clin Neurosci. 2015;22:1837-9.

85. Rao PJ, Ghent F, Phan K, et al. Stand-alone anterior lumbar interbody fusion for treatment of degenerative spondylolisthesis. J Clin Neurosci. 2015;22:1619-24

86. Mobbs RJ, Phan K, Thayaparan GK, et al. Anterior Lumbar Interbody Fusion as a Salvage Technique for Pseudarthrosis following Posterior Lumbar Fusion Surgery. Global Spine J. 2016;6(1):14-20.

87. Ozgur BM, Aryan HE, Pimenta L, et al. Extreme Lateral Interbody Fusion (XLIF): a novel surgical technique for anterior lumbar interbody fusion. Spine J. 2006;6:435-43. 88. Arnold PM, Anderson KK, McGuire RA Jr. The lateral transpsoas approach to the lumbar and thoracic spine: A review. Surg Neurol Int. 2012;3:S198-215.

89. Malham GM, Parker RM, Goss B, et al. Clinical results and limitations of indirect decompression in spinal stenosis with laterally implanted interbody cages: results from a prospective cohort study. Eur Spine J. 2015;24(Suppl 3):339-45.

90. Barbagallo GM, Albanese V, Raich AL, et al. Lumbar Lateral Interbody Fusion (LLIF): Comparative Effectiveness and Safety versus PLIF/TLIF and Predictive Factors Affecting LLIF Outcome. Evid Based Spine Care J. 2014; 5:28-37.

91. Silvestre C, Mac-Thiong JM, Hilmi R, et al. Complications and Morbidities of Mini-open Anterior Retroperitoneal Lumbar Interbody Fusion: Oblique Lumbar Interbody Fusion in 179 Patients. Asian Spine J. 2012;6:8997.

92. Ohtori S, Orita S, Yamauchi K, et al. Mini-Open Anterior Retroperitoneal Lumbar Interbody Fusion: Oblique Lateral Interbody Fusion for Lumbar Spinal Degeneration Disease. Yonsei Med J. 2015;56:1051-9.

93. Phan K, Mobbs RJ. Oblique lumbar interbody fusion for revision of non-union following prior posterior surgery: a case report. Orthopaedic Surgery. 2015;7(4):364-7.

94. Kowalski RJ, Ferrara LA, Benzel EC. Biomechanics of bone fusion. Neurosurg Focus. 2001;10:E2.

95. Dorward IG, Lenke LG, Stoker GE, et al. Radiographic and Clinical Outcomes of Posterior Column Osteotomies in Spinal Deformity Correction. Spine. 2014;39(11):870-880. 96. Burkus JK, Gornet MF, Dickman CA, et al. Anterior lumbar interbody fusion using rhBMP-2 with tapered interbody cages. J Spinal Disord Tech. 2002;15:337-49.

97. Pavlov PW, Meijers H, van Limbeek J, et al. Good outcome and restoration of lordosis after anterior lumbar interbody fusion with additional posterior fixation. Spine. 2004;29:1893-9; discussion 1900

98. Kim JS, Kang BU, Lee SH, et al. Mini-transforaminal 
lumbar interbody fusion versus anterior lumbar interbody fusion augmented by percutaneous pedicle screw fixation: a comparison of surgical outcomes in adult low-grade isthmic spondylolisthesis. J Spinal Disord Tech. 2009;22:114-21.

99. Faundez AA, Schwender JD, Safriel Y, et al. Clinical and radiological outcome of anterior-posterior fusion versus transforaminal lumbar interbody fusion for symptomatic disc degeneration: a retrospective comparative study of 133 patients. Eur Spine J. 2009;18:203-11.

100. Kanter AS, Mummaneni PV. Minimally invasive spine surgery. Neurosurg Focus. 2008;25(2): E1.

101. Harris EB, Massey P, Lawrence J, et al. Percutaneous techniques for minimally invasive posterior lumbar fusion. Neurosurg Focus. 2008;25:E12.

102. Kan P, Schmidt MH. Minimally invasive thoracoscopic approach for anterior decompression and stabilization of metastatic spine disease. Neurosurg Focus. 2008;25:E8 103. Assaker R. Minimal access spinal technologies: stateof-the-art, indications, and techniques. Joint Bone Spine. 2004;71:459-69.

104. Foley KT, Gupta SK. Percutaneous pedicle screw fixation of the lumbar spine: preliminary clinical results. J Neurosurg. 2002;97(Suppl. 1):7-12.

105. Oppenheimer JH, DeCastro I, McDonnell DE. Minimally invasive spine technology and minimally invasive spine surgery: a historical review. Neurosurg Focus. 2009;27:E9.

106. Holly LT, Schwender JD, Rouben DP, et al. Minimally invasive transforaminal lumbar interbody fusion: indications, technique, and complications. Neurosurg Focus. 2006;20:E6 